\title{
Mediation Techniques in Secondary Education should take into Account Gender Differences for Enhanced Effectiveness: Evidence from Secondary Schools in Catalonia
}

\author{
By Juan Pedro Aznar Alarcón * \\ Lisandro Castillo ${ }^{\dagger}$ \\ Teresa Duplá Marín +
}

\begin{abstract}
International institutions and national and regional governments are promoting a culture that includes the use of mediation in secondary schools. The literature review and the previous empirical research suggest that the introduction of mediation as an alternative method for conflict resolution helps improve school climate, thus improving the students' perception of school life and helping achieve better academic results. Furthermore, it contributes to the development of certain skills, such as a spirit of team work, empathy and better communication that would be very useful in their adult lives. However, in order to design efficient mediation systems, we must first understand how students feel about and react to mediation training. This research has been conducted in five different secondary schools in the city of Barcelona and its outskirts. A total of 367 students responded to a survey on school climate and their feelings about mediation. The focus of the analysis was to find statistically significant differences according to gender regarding how efficient and useful students consider mediation to be as an alternative means of conflict resolution. Girls give higher average values when asked whether mediation has been explained and used, and they find it more useful than their male peers.
\end{abstract}

Keywords: conflict management, peer mediation, school climate, gender differences, bullying, secondary schools.

\section{Introduction}

Continuous violence (bullying) at school has been identified as a predictor of later criminality (Olweus, 2012), and at the same time, the increased resilience to violent radicalization through early schooling has become a main concern in Europe. In a cross-national study, Ortega et al. (2012) analyzed the psychological impact of bullying and cyber-bullying on students. One of the conclusions is

\footnotetext{
*Associate Professor, Economics, Business and Accounting Department, ESADE Business and Law School, Universitat Ramon Llull, Member of the Management Conflict Group at ESADE Law School, Spain.

†Research Assistant, ESADE Business and Law School. Universitat Ramon Llull, Member of the Management Conflict Group at ESADE Law School, Spain.

${ }^{+}$Full Professor, ESADE Law Department, ESADE Business and Law School, Universitat Ramon Lllull, Director of the Management Conflict Group at ESADE Law School, Spain.
} 
that the negative effects can clearly be long term in nature. Academic and psychosocial problems, the lack of self-esteem, depression and externalized hostility are among the consequences of bullying among victims. Some systematic efforts to remedy this issue have been made in several European countries, such as the systematic assessment of conflict at school designed by the Regional Government of Catalonia (Generalitat de Catalunya, 2001; 2006; 2012), in Spain. It has been observed that since peer mediation was promoted in the school system as a preferential way to solve conflicts among students, an internal change of the conflict structure has begun. This change consists in that the average number of bullying incidents at school remains globally stable, but the amount of bullying among boys and girls is changing in a similar proportion over time (Generalitat de Catalunya, 2012; Gómez \& Álvarez-González, 2015; Wearmouth, Mckinney, \& Glynn, 2007).

Could this change be due to a different way in which boys and girls relate to the peer mediation techniques? Turnuklu et al. (2010) and Garaigodobil and Martínez-Valderrey (2015) have reported experiences with this phenomenon. They both applied the same experimental method to separate samples of boys and girls in Turkey and Spain. The results show, in both cases, that boys and girls have used the mediation techniques differently, in such a way that boys change the way they solve conflicts once they have been trained in peer mediation, progressing from a strategy involving force to one relying on cooperation. This was not the case with girls, as they already used cooperative strategies to solve problems, and thus the change was not significant in terms of the average number of girls who use cooperative strategies to solve conflicts (Garaigordobil \& Martínez-Valderrey, 2015; Turnuklu et al., 2010).

In different research studies, Breivik and Olweus (2014) and Turnuklu et al. (2010) have proven that boys and girls expressed a different kind of violence, depending on the gender of the person to whom it was directed to, i.e., to another girl or boy. Upon finding this difference, these authors began to evaluate the need for different assessment instruments, which take into account gender differences (Breivik \& Olweus, 2014; Olweus, 1998; 2013; Turnuklu et al., 2010; Turnuklu, Kacmaz, Sunbul, \& Ergul, 2009). It has also been observed that girls have a stronger emotional reaction to peer conflicts, and boys have a stronger emotional reaction when the conflict involves the school system (Ceballos et al., 2012). On the other hand, conflicts among peers tend to decrease with age, while conflicts related to the school system increase with age (Ceballos et al., 2012; Generalitat de Catalunya, 2012).

All this research and the confirmed facts suggest that gender-oriented mediation techniques could be possible and yield advantageous results. First, however, evidence of gender differences is needed. Thus, the aim of our analysis was to find significant differences according to gender in the way in which students engage in mediation, and what they think about its outcome. The results of this research suggest that it is possible to design efficient systems of conflict management in secondary schools that take into account gender differences, thus serving as an efficient tool to provide individuals with the skills they need to manage conflicts. It should be noted that this is a basic competence that 
individuals will use through their entire lives in many different areas, in response to both professional and personal issues.

\section{Literature Review}

Athansiades and Deliyanni-Kouimtizis (2010) analyzed gender differences among Greek students regarding their experience with bullying. A total of 95 students ranging from ages 15 to 16 years old participated in focus group interviews. According to their results, boys actively participate in bullying more than girls. Girls tend to use verbal or more indirect ways of bullying. In general terms, girls have a tendency to support or understand the victims, whereas boys accept and show more understanding for the aggressor. Girls show a greater propensity than boys to share their experiences with bullying, both as victims and witnesses, with their parents or close friends. Yubero and Navarro (2006) performed a quantitative analysis of Spanish students to determine any possible gender differences; one of their main findings associated a more impulsive character with boys. Boys also consider violence by boys directed to girls to be more unacceptable than violence among boys, which is considered more acceptable by both genders.

Pearce et al. (2011) summarized the empirical evidence on the best practices in schools to handle different forms of bullying, with special emphasis on the new forms of bullying (mainly cyber-bullying). The evidence suggests that the best approach is one in which everyone in the school is involved, as a wholeschool approach is needed for a problem of such complexity. Many different programs have been implemented to improve school climate and to reduce the presence of bullying behaviours. Among these programs, peer mediation has been one of the most popular. Burell, Zirbel and Allen (2006) conducted a meta-analysis to find evidence on the efficiency of peer mediation as a tool to improve school climate. Their main result was a 93\% success rate in mediation procedures, meaning that in 93 of every 100 cases, mediation ended with a resolution that was accepted by all the parties involved. The rate of satisfaction with the agreement reached was $83 \%$. Most of the studies considered in their analysis conclude that peer mediation has a clearly positive impact on school climate. A fourth positive result from mediation is the noticeable decrease in the number of disciplinary interventions in schools where mediation programs have been developed. The students who acted as mediators showed an improvement in their skills used to resolve interpersonal conflicts after receiving appropriate training.

Rose and Rudolph (2006) conducted extensive research focusing on what has been published in prestigious journals on gender differences in the behaviour of boys and girls, and their peer-relationships. They concluded, firstly, that boys interact with same sex-peers more frequently than girls. Secondly, girls are more pro-social than boys in early adolescence. In general, the existing sex differences become more consistent with age. It is clear that the existence of these differences can have a potential effect on how girls and boys understand 
and use peer mediation.

One of the most frequently cited papers on the effects of mediation in schools is the pioneering work of Johnson and Johnson (1996). According to their research, the positive effects of peer mediation are clear. Students often tend to solve conflicts in destructive ways that do not take into account the other party involved; however, students trained in mediation use the skills learned over long periods of time. They solve conflicts in a more constructive way, taking into account the other party. Another important outcome is that the number of suspensions and problems among students decrease, as do those with the school administration and teachers. The improvement in school climate can have positive effects, favouring the learning process in the classroom and throughout the entire school. More recently, Peterson and Skiba (2001) made an effort to find evidence in US secondary schools regarding the best policies for creating a school climate that rejects violence. One of the policies that are strongly recommended is the development of mediation training for students who then act as mediators in peer conflicts. Although they recognize that these programs have expanded quicker than the capacity of the scholars to analyze their effects, according to these authors, some of the available evidence suggests that peer mediation training has long-term positive effects on the students who have received the training, which teachers and students alike believe is one way to improve school climate, and thanks to peer mediation training, students change the way they understand and react to conflicts. However, as these authors have pointed out, more research is necessary on mediation, how it is carried out, how it is perceived and its effects, both in the short run, in terms of school climate, but also in the long run, as a way to give students valuable skills in terms of communication, empathy and team work. This article is an attempt to work in this direction.

\section{Methodology}

Based on questionnaires previously used by various scholars (Bekken et al., 2015; Breivik \& Olweus, 2014; Garaigordobil \& Martínez-Valderrey, 2015; Generalitat de Catalunya, 2001, 2012; McWilliam, 2010; Turnuklu et al., 2009) to assess the importance of mediation as a way to address conflict management and the effectiveness of mediation as a tool for improving the school environment, a new questionnaire was designed. To validate the questionnaire, it was sent to the head of studies of 15 different schools, teachers involved in the peer mediation system at some of the schools, several technical staff members at the Educational Department of the Regional Government and some experts on conflict management. Three weeks later, on March $15^{\text {th }}$, the document was discussed with them, and a final version was drafted as a result of their feedback.

This questionnaire classifies questions in 4 different categories. The first category is a set of questions to identify the respondent profile, and it contains questions related to in which year the student is in school, the school, gender, nationality, the parents' nationality and what kind of activities the student does after school, differentiating individual activities, such as playing a musical 
instrument or athletic training, from activities involving working with others, such as theatre or playing on a football team. Our results failed to show any significant difference according to the different activities in which the students were involved. The questionnaire also included a question about how much time students spend daily with their parents; again, there is no evidence of a correlation between time spent and the percentage of students that can be considered aggressors or victims. The second group of questions attempts to identify the role played by the student as a victim, a witness or the person responsible for physical or verbal aggressions. It is interesting to note that the Regional Government conducts a survey every 4 years, and our percentages of victims and aggressors are very similar to those obtained by the Government in a large sample. The third set of questions are aimed at determining how much the student knows about mediation, what effort the school has made to promote it and how it has often been used. Finally, the last set of questions is related to the students' perception of the main benefits associated with mediation techniques. Most of the questions that asked students about their own perceptions used a Likert scale to rate their responses from 1 to 5 .

The questionnaire was distributed in May 2016 to students in 5 different schools, obtaining 367 completed questionnaires. The questionnaire was answered on line and some instructions were given by the group tutors about the process before the students answered it. Students had one hour to answer the questionnaire, and they were allowed to skip any question they did not want to answer and to ask any questions they wished in order to understand the questions. They were informed that the questionnaires were being used in a research study and special emphasis was placed on the confidentiality of their responses. At the end of the questionnaire, students had the opportunity to comment on anything they considered relevant.

The survey was distributed equally between the two genders. $50.54 \%$ of the sample students were girls and $49.46 \%$ were boys. The sample consisted of students from one of the four years that make up compulsory secondary education in Spain, with students typically ranging in age from 12 to 16 years. $32.09 \%$ were students in their first year in secondary school, $16.3 \%$ were studying their second year, $30.21 \%$ were in their third year, and finally, the remaining $19.52 \%$ were studying their fourth year.

Based on the previous scholars' results and what our data suggests, the aim of our analysis is to find a significant difference according to gender in how students engage with mediation and what they think about its outcome. Based on the previous literature and on the interviews with mediation experts, teachers responsible for mediation services and the heads of secondary schools, we tested the following three hypotheses:

H1: Victims and aggression profiles are more frequent among boys in secondary education.

$\mathrm{H} 2$ : Girls in secondary education are more involved in the mediation culture promoted by schools.

H3: Girls in secondary school take greater advantage of the positive aspects 
related to mediation in terms of the improvement of personal skills.

To test these hypotheses, the Mann-Whitney $U$ test was used to verify whether the mean of the two subsamples could be considered different. This nonparametric test has the advantage of being able to be used with non-normal distributions, such as the ones represented by our data. The null hypothesis is that both distributions, male and female students, have the same average value. The alternative hypothesis is that there is a difference between the associated values, depending on gender. The prerequisite step for using the MannWhitney U test, checking normality, has been carried out using the ShapiroWilk test. The result is that the distributions are non-normal for all variables measured by the questionnaire.

\section{Results}

Students were asked to rate themselves as victims or aggressors on a Likert scale of 1 to 5 . Their results by gender are shown in graphs 1 and 2. Victimization or aggression was considered to occur when the score assigned in the answers reached a value of 3 or higher, similar to the criterion used in other surveys (Generalitat de Catalunya, 2001; 2006; 2012). Figure 1 refers to the behaviour of aggressors, whereas Figure 2 refers to the percentage of students who can be considered victims. The two graphs differentiate by gender and also between physical and verbal aggression. As expected, the rate of physical aggression is higher for boys than girls, with rates of $6.47 \%$ and $2.27 \%$, respectively. Verbal aggressions show a higher percentage than physical aggressions, but again with a higher incidence in the case of boys (23.02\% as opposed to $9.09 \%$ for girls). Similarly, Figure 2 shows a higher incidence of victims for boys than it does for girls, but the difference by gender is much less pronounced as compared to the incidence of the aggressors. $4.30 \%$ of boys scored a value 3 or more on a scale of 1 to 5, identifying them as victims of physical aggressions; in the case of girls, the percentage is only $3.79 \%$. When asked to assess whether they considered themselves to be victims of verbal aggressions, the rate was multiplied by a factor of nearly 4 as compared to physical aggressions. 
Figure 1. Aggressors by Gender

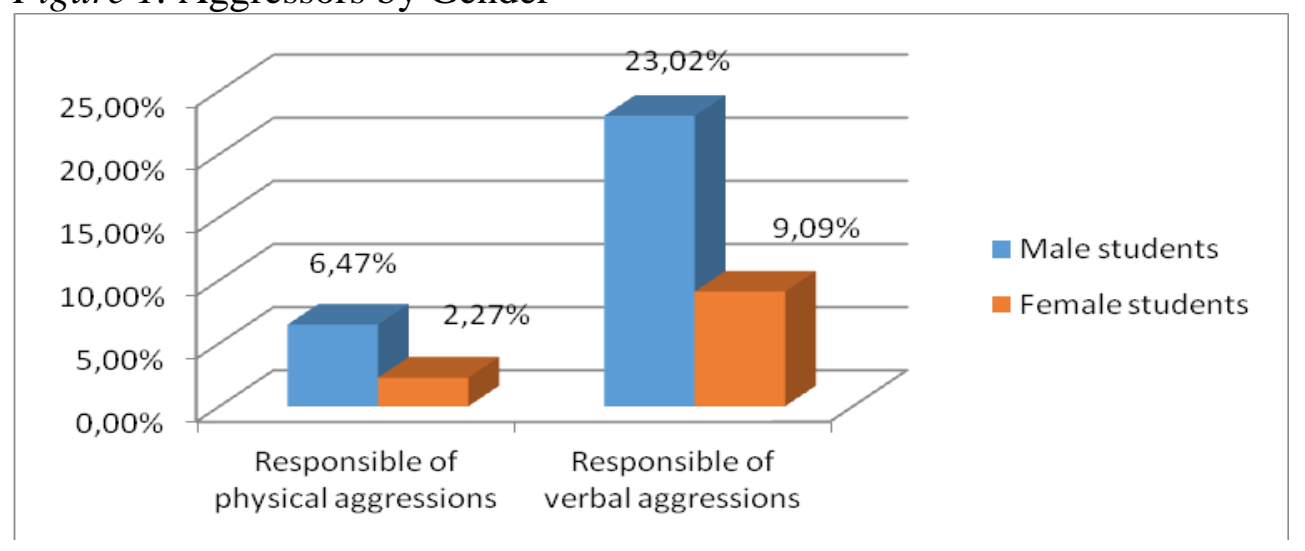

Figure 2. Victims by Gender

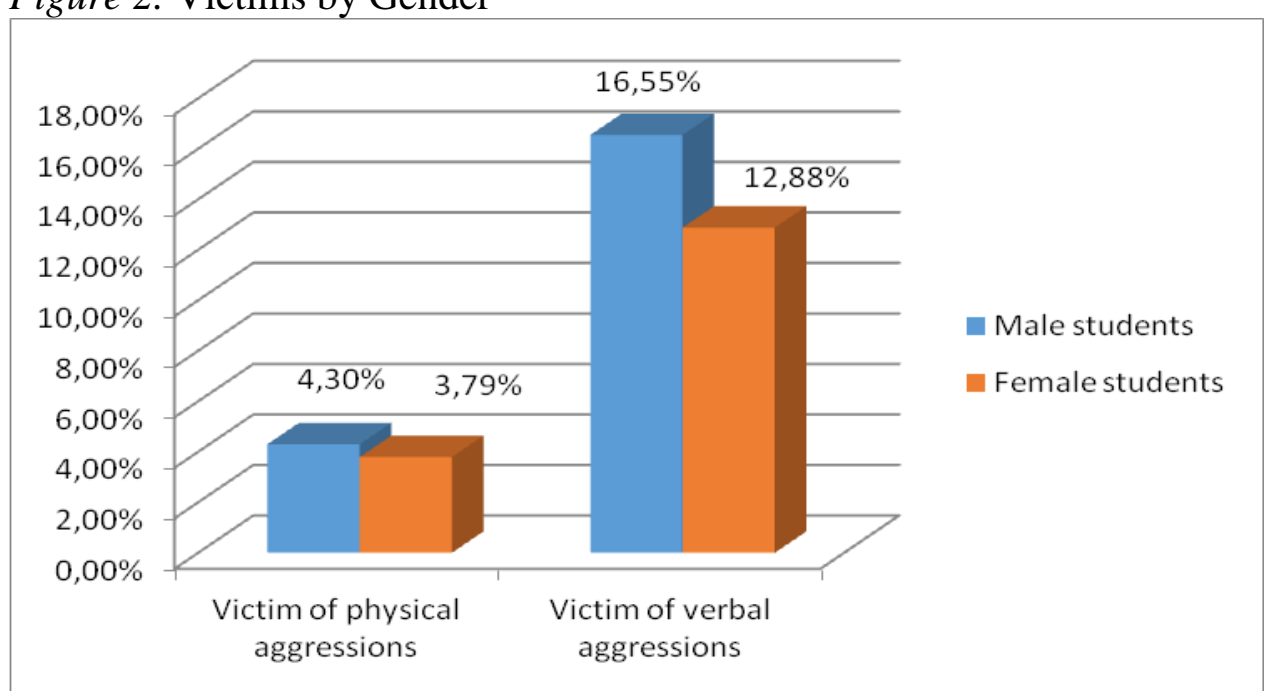

To assess the extent to which mediation was explained and used at school, students were asked to express their level of agreement with a series of statements, according to a Likert scale ranging from 1 to 5 , on which 1 meant total disagreement and 5 total agreement. The questions covered the level of discipline at the school, how much they thought tutors were taking care of them, the extent to which much mediation was explained in class, the extent to which mediation was used and their valuation of mediation as an effective tool for solving conflicts. The results by gender are summarized in Table 1 .

Table 1. The Use of Mediation and Valuation by Students. Differences by Gender

\begin{tabular}{|l|c|c|}
\hline & $\begin{array}{c}\text { Male } \\
\text { Students }\end{array}$ & $\begin{array}{c}\text { Female } \\
\text { Students }\end{array}$ \\
\hline How tough is discipline at the school & 2.51 & 2.07 \\
\hline How much the tutor takes care of students & 3.50 & 3.71 \\
\hline The extent to which mediation has been explained & 3.75 & 4.18 \\
\hline The extent to which mediation has been used & 3.36 & 3.87 \\
\hline $\begin{array}{l}\text { How useful mediation is as a tool for conflict } \\
\text { management }\end{array}$ & 3.80 & 4.02 \\
\hline
\end{tabular}


As can be observed in Table 1, male students consider discipline at school to be tougher than female students, even though both score discipline below 3 . Concerning the extent to which mediation has been explained and is considered as a tool for conflict management, female students score higher than male students. Because mediation can have effects on many different levels, both individually and also affecting the school environment, a last set of questions was asked. Again, students expressed their level of agreement with the statements according to a 5-point Likert scale. Table 3 shows the average values for this last part of the questionnaire.

Table 2. What is Mediation Useful for? Differences by Gender

\begin{tabular}{|l|c|c|}
\hline & $\begin{array}{c}\text { Male } \\
\text { Students }\end{array}$ & $\begin{array}{c}\text { Female } \\
\text { Students }\end{array}$ \\
\hline Mediation improves the school environment & 2.84 & 3.00 \\
\hline Mediation is a better way to solve conflicts & 2.90 & 3.20 \\
\hline Mediation is useful to improve empathy & 2.99 & 3.34 \\
\hline Mediation is useful to improve dialogue skills & 2.94 & 2.98 \\
\hline I prefer rules over the mediation process & 2.76 & 2.75 \\
\hline
\end{tabular}

As can be observed in Table 2, only female students rate mediation as useful for improving the school environment, solving conflicts and increasing empathy. Scores are different between male and female students and the mean for male students does not reach the minimum score of 3 in order for mediation to be considered useful. The main findings in terms of accepting or rejecting our research hypothesis are summarized in Table 3 . Table 3 presents the results of variable comparisons, showing statistical significance at a 1 and 5\% level of confidence.

Table 3. Statistically Significant Differences between Genders

\begin{tabular}{|l|c|c|c|}
\hline & $\begin{array}{c}\text { Male } \\
\text { Students }\end{array}$ & $\begin{array}{c}\text { Female } \\
\text { Students }\end{array}$ & $\begin{array}{c}\text { Statistical } \\
\text { Significance }\end{array}$ \\
\hline Responsible for physical aggressions & 1.30 & 1.08 & $\begin{array}{c}\text { At a 1\% level of } \\
\text { confidence }\end{array}$ \\
\hline Responsible for verbal aggressions & 2.02 & 1.41 & $\begin{array}{c}\text { At a 1\% level of } \\
\text { confidence }\end{array}$ \\
\hline Victim of physical aggressions & 1.2 & 1.18 & Not significant \\
\hline Victim of verbal aggressions & 1.69 & 1.57 & Not significant \\
\hline Mediation has been explained at school & 3.73 & 4.18 & $\begin{array}{c}\text { At a 1\% level of } \\
\text { confidence }\end{array}$ \\
\hline Mediation is used at school & 3.38 & 3.90 & $\begin{array}{c}\text { At a 5\% level of } \\
\text { confidence }\end{array}$ \\
\hline How tough is school discipline & 2.51 & 2.00 & $\begin{array}{c}\text { At a 1\% level of } \\
\text { confidence }\end{array}$ \\
\hline How useful is mediation & 3.81 & 4.03 & Not significant \\
\hline Mediation is considered a valuable tool & 2.68 & 3.21 & Not significant \\
\hline Mediation improves the school environment & 2.82 & 3.02 & Not significant \\
\hline Mediation helps improve personal empathy & 3.00 & 3.35 & Not significant \\
\hline Mediation helps improve dialogue skills & 2.96 & 2.98 & Not significant \\
\hline
\end{tabular}


As can be observed in Table 3, significant differences have been found in 5 of the questions the students were asked. The first two differences refer to being responsible for physical or verbal aggressions, in which boys display a higher score. On two other variables, girls demonstrate that they are more conscious of the mediation efforts, and finally, boys seem to react more strongly to discipline as compared to girls.

\section{Discussion}

Our analysis is consistent with data from similar studies (Hernáez \& García, 2014; Muñoz, Lucer, Comejo, Muñoz, \& Araya, 2014; Padros, 2014; Thompkins, Chauveron, Harel, \& Perkins, 2014). The results suggests that physical aggressions and verbal aggressions are more common among boys than girls (Garaigordobil \& Martínez-Valderrey, 2015; Olweus, 1998; Turnuklu et al., 2010; 2009). In schools where an effort has been made to use mediation, girls seem to be more sensitive to what it means and more willing to use it. Considering their assessment of the possible positive effects associated with mediation, the data show higher values for all items for girls than for boys, suggesting that girls have a more positive attitude towards mediation and its effects, or at least that girls already thought that mediation is a way of managing conflict favorably. This attitude could be the reason why a positive relationship has been detected between choosing a girl as a mediator and the feeling of been listened to during a mediation process (McWilliam, 2010).

Considering that mediation can have effects on many levels, both individually and also affecting the school environment, previous empirical studies show that mediation can reduce the level of conflict, helping improve the environment in terms of different kinds of violent behavior (McWilliam, 2010; Christmann, 2012; Doosje, Loseman, \& van den Bos, 2013; Konold \& Cornell, 2015). Mediation can also have individual effects, helping students develop skills such as empathy or dialogue skills, and improving relationships among students (McWilliam, 2010; Padros, 2014). In terms of each hypothesis, our findings and their statistical significance were as follows:

Hypothesis 1: There is a statistically significant difference according to gender in how students identify themselves as being responsible for verbal and physical aggressions. However, the difference is not present in terms of their role as witnesses or victims. The average value, on a Likert scale of 1 to 5 , is 1.3 for male students and 1.08 for female students. The difference is significant at a $1 \%$ level of confidence.

Hypothesis 2: When students are asked whether mediation had been explained at school, the average score according to gender is different, but not statistically significant. When the question is about how mediation is used, the average for women students is 3.90 and 3.38 for male students. The level of confidence is $1 \%$, so we can consider this to be a significant difference according to gender. An interesting result is how students perceive discipline at school. When asked about how tough the discipline regime is that is applied at school, 
the average value for boys is 2.51 , whereas the average value for girls is just 2.00. This difference is significant at a $1 \%$ level of confidence.

Hypothesis 3: The last hypothesis to check is related to whether the outcome of mediation is perceived differently, depending on gender. The statements students were asked to assess on a scale of 1 to 5 were the extent to which mediation improves the school environment, the extent to which it is a good tool to manage conflict and, from an individual perspective, whether mediation has helped improve their empathy and dialogue skills. The average values are higher for the female students' sample. When asked about whether mediation improves the school environment, the mean is 3.02 for girls as opposed to 2.82 for the boys' subsample. When asked whether they consider it a valuable tool, the mean is 3.21 for female students, as compared to 2.68 for male students. Similar results are obtained regarding how mediation helps build personal skills. A positive effect on empathy has a value of 3.35 for girls and 3.00 for boys. If the analysis focuses on improving dialogue skills, the value is 2.98 for girls as opposed to 2.96 for boys, making it the variable with the narrowest difference in terms of gender.

\section{Conclusions}

There is an increasing effort made by international and national organizations to promote a culture of dialogue and to provide citizens with the skills needed to manage conflict in more efficient ways. National educational systems are making efforts to promote alternative ways to resolve disputes, with peer mediation being one of the most common. Even supranational entities like the European Union have taken action to promote a culture of dialogue in schools. Mediation and other alternatives for conflict management are faster and more efficient in terms of the cost-benefit analysis, according to the literature review and previous empirical research in different countries and cultures. In order to develop a real culture of mediation, the first step is to provide training and experience at school for both teachers and students. In many countries, the regulation of the educational system has included subjects or other elements related to conflict culture management in the national curricula (Chrispino \& Dusi, 2008; Mestry, 2015). One important element immediately emerges. Are there differences by gender in how much conflict arises and the type of conflict? Do male and female students have a different approach towards mediation? The answer to these questions is fundamental if we want to develop an efficient system of mediation in secondary schools.

Some of our results reinforce what has already been said by the previous research in this field. Conflict, both verbal and physical, is more common among boys than girls. Our research gives some new insights into how boys and girls perceive the efforts to promote mediation by schools and how they value the results of these efforts. Boys are by far more concerned with discipline, and they find the discipline tougher than girls. On the other hand, in the same environment, girls are more sensitive to mediation, which they rank with higher values when 
asked if mediation has been explained or used at school. These results are significant from a statistical point of view. One interesting topic for further work in the future is the values associated with mediation. We can measure what students think about, how mediation improves the school environment or whether it has positive effects on an individual basis, in the form of greater empathy or better skills in terms of dialogue with others. Girls scored higher than boys on all the items measured, but an effort must be made to work with larger and broader samples to confirm whether these differences are significant. If we are capable of understanding why girls have a more positive attitude towards mediation, or what may be the same, what makes mediation less attractive to boys then we can adjust the mediation systems we apply, acknowledging these differences and making them more efficient.

This research is the starting point for future research that will attempt to find out why the answers to these questions are different by gender. Future research in other countries and with larger samples can reinforce the results obtained. Additional quantitative and qualitative research must also address the factors that explain the differences in the perception of mediation by gender in order to understand how to develop conflict resolution systems through the promotion of individual conflict management skills. These constitute a basic competence that individuals will use throughout their entire lives in many different areas, addressing both professional and personal issues.

\section{References}

Athanasiades, C., \& Deliyanni-Kouimtzis, V. (2010). The experience of bullying among secondary school students. Psychology in the Schools, 47(4), 328-341.

Bekken, F., Beld, M., Roest, J., Dekker, A., de Valk, S., van Miert, V., van der Helm, P., Stams, G.J.J.M. (2015). SCI: School Climate Inventory. Retrieved from http://bit.ly/ 2r9slq6.

Breivik, K., \& Olweus, D. (2014). An item response theory analysis of the Olweus Bullying scale. Aggressive Behavior, 41(1), 1-13. http://doi.org/10.1002/ AB.21571

Burrell, N.A., Zirbel, C.S., \& Allen, M. (2006). Evaluating peer mediation outcomes in educational settings: A meta-analytic. Classroom communication and instructional processes: Advances through meta-analysis. Retrieved from http://bit.ly/2s3vjzN.

Ceballos Vacas, E.M., Correa Rodríguez, N.T., Correa Piñero, A.D., Rodríguez Hernández, J.A., Rodríguez Ruiz, B., \& Vega Navarro, A. (2012). La voz del alumnado en el conflicto escolar: The Student Perspective in School Conflicts. Revista de Educación, 359, 554-579.

Chrispino, A., \& Dusi, M.L.H.M. (2008). Uma proposta de modelagem de política pública para a redução da violência escolar e promoção da Cultura da Paz [A proposal for a public policy model aimed to reduce school violence and promote a peace culture]. Ensaio: Aval Pol Públ Educ, 16(61), 597-624. http://doi.org/ 10.1590/S0104-40362008000400007.

Christmann, K. (2012). Preventing religious radicalisation and violent extremism: A systematic review of the research evidence. Review of the Research Evidence. Research Report. Youth Justice Board.

Doosje, B., Loseman, A., \& Bos, K. (2013). Determinants of radicalization of Islamic 
youth in the Netherlands: Personal uncertainty, perceived injustice, and perceived group threat. Journal of Social Issues, 69(3), 586-604. http://doi.org/10.1111/ josi. 12030 .

Garaigordobil, M., \& Martínez-Valderrey, V. (2015). The effectiveness of Cyberprogram 2.0 on conflict resolution strategies and self-esteem. Journal of Adolescent Health, 57(2), 229-234. http://doi.org/10.1016/j.jadohealth.2015. 04.007.

Generalitat de Catalunya. (2001). Joventut $i$ seguretat a Catalunya. 2001 [Youth and security in Catalonia. 2001]. Retrieved from http://bit.ly/2rcLCGa.

Generalitat de Catalunya. (2006). Encuesta de Convicencia escolar y seguridad en Cataluña. 2006. [Survey on school climate and security in Catalonia. 2006]. Barcelona. Retrieved from http://bit.ly/2sJTqBj.

Generalitat de Catalunya. (2012). Ensenyament secundari (curs 2011-2012) [Secondary school report, academic year 2011-2012]. Barcelona. Retrieved from http://bit.ly/ 2skSczi.

Gómez, M.J.V., \& Álvarez-González, B. (2015). Perfiles y percepciones de género en violencia escolar [Gender profiles and perceptions in terms of school violence]. Revista de Investigación Educativa, 33(1), 211-231. http://doi.org/10.6018/rie. 33.1.195891.

Hernáez, L.L., \& García, A.R. (2014). Medidas disciplinarias en los centros educativos: ¿suficientes contra el acoso escolar? [Disciplinary measures in schools. Are they enough to fight bullying?] Perfiles Educativos, 36(145), 32-50. http://doi.org/10. 1016/S0185-2698(14)70636-1.

Johnson, D.W., \& Johnson, R.T. (1996). Conflict resolution and peer mediation programs in elementary and secondary schools: A review of the research. Review of Educational Research, 66(4), 459-506.

Konold, T.R., \& Cornell, D. (2015). Measurement and structural relations of an Authoritative School Climate model: A multi-level latent variable investigation. Journal of school Psychology, 53(6), 447-461. http://doi.org/10.1016/j.jsp.2015. 09.001.

McWilliam, N. (2010). A school peer mediation program as a context for exploring therapeutic jurisprudence (TJ): Can a peer mediation program inform the law? International Journal of Law and Psychiatry, 33(5), 293-305. http://doi.org/10. 1016/j.ijlp.2010.09.002.

Mestry, R. (2015). Exploring the forms and underlying causes of school-based violence: implications for school safety and security. Anthropologist, 19(3), 655-663.

Muñoz Quezada, M.T., Lucero Moncada, B.A., Cornejo Araya, C.A., Muñoz Molina, P.A., \& Araya Sarabia, N.E. (2014). Convivencia y clima escolar en una comunidad educativa inclusiva de la Provincia de Talca, Chile [Socialization and school climate in an inclusive learning community in the province of Talca, Chile]. Revista Electrónica de Investigación Educativa, 16(2), 16-32.

Olweus, D. (1998). Conductas de acoso y amenaza entre escolares [Bullying and threats among schoolchildren]. Ediciones Morata.

Olweus, D. (2012). Cyberbullying: An overrated phenomenon? European Journal of Developmental Psychology, 9(5), 520-538.

Olweus, D. (2013). School bullying: Development and some important challenges. Annual Review of Clinical Psychology, 9, 751-780. http://doi.org/10.1146/annu rev-clinpsy-050212-185516.

Ortega, R., Elipe, P., Mora-Merchán, J.A., Genta, M.L., Brighi, A., Guarini, A., \& Tippett, N. (2012). The emotional impact of bullying and cyberbullying on victims: a European cross-national study. Aggressive Behavior, 38(5), 342-356.

Padrós, M. (2014). A transformative approach to prevent peer violence in schools: 
contributions from communicative research methods. Qualitative Inquiry, 20(7), 916-922. http://doi.org/10.1177/1077800414537217.

Pearce, N., Cross, D., Monks, H., Waters, S., \& Falconer, S. (2011). Current Evidence of Best Practice in Whole-School Bullying Intervention and Its Potential to Inform Cyberbullying Interventions. Australian Journal of Guidance and Counseling, 21(01), 1-21.

Peterson, R. L., \& Skiba, R. (2001). Creating school climates that prevent school violence. The Clearing House, 74(3), 155-163.

Rose, A. J., \& Rudolph, K. D. (2006). A review of sex differences in peer relationship processes: potential trade-offs for the emotional and behavioral development of girls and boys. Psychological Bulletin, 132(1), 98.

Thompkins, A.C., Chauveron, L.M., Harel, O., \& Perkins, D.F. (2014). Optimizing violence prevention programs: An examination of program effectiveness among urban high school students. Journal of School Health, 84(7), 435-443.

Turnuklu, A., Kacmaz, T., Gurler, S., Turk, F., Kalender, A., Zengin, F., \& Sevkin, B. (2010). The effects of conflict resolution and peer mediation training on Turkish elementary school students' conflict resolution strategies. Journal of Peace Education, 7(1), 33-45.

Turnuklu, A., Kacmaz, T., Gurler, S., Sevkin, B., Turk, F., Kalender, A., \& Zengin, F. (2010). The effects of conflict resolution and peer mediation training on primary school students' level of aggression. Education 3-13, 38(1), 13-22. http://doi.org/ $10.1080 / 03004270902760668$.

Turnuklu, A., Kacmaz, T., Sunbul, D., \& Ergul, H. (2009). Does peer-mediation really work? Effects of conflict resolution and peer-mediation training on high school students' conflicts. Procedia-Social and Behavioral Sciences, 1(1), 630-638. http://doi.org/10.1016/j.sbspro.2009.01.112.

Wearmouth, J., Mckinney, R., \& Glynn, T. (2007). Restorative justice in schools: A New Zealand example. Educational Research, 49(1), 37-49. http://doi.org/10.1080/00 131880701200740.

Yubero, S., \& Navarro, R. (2006). Students' and teachers' views of gender-related aspects of aggression. School Psychology International, 27(4), 488-512. 
